\title{
Complete mitochondrial genome of the Liuyang black goat and its phylogenetic relationship with other Caprinae
}

\author{
S. Chen ${ }^{1,2}$, H.M. Ma ${ }^{1}$, G.S. Chen ${ }^{2}$ and L.Y. Wang ${ }^{1}$ \\ ${ }^{1}$ College of Animal Science and Technology of Hunan Agricultural University, \\ Changsha, China \\ ${ }^{2}$ College of Animal Science and Technology of Gansu Agricultural University, \\ Lanzhou, China \\ Corresponding authors: H.M. Ma / G.S. Chen \\ E-mail: mahaiming2000@163.com / 284858600@qq.com \\ Genet. Mol. Res. 15 (2): gmr.15018267 \\ Received December 14, 2015 \\ Accepted January 29, 2016 \\ Published July 15, 2016 \\ DOI http://dx.doi.org/10.4238/gmr.15028267
}

\begin{abstract}
In this study, the complete mitochondrial genome sequence of the Liuyang black goat was investigated, and phylogenetic relationships between the Liuyang black goat and other species of Caprinae were analyzed. The total length of the mitochondrial genome was $16,715 \mathrm{bp}$, which consisted of $33.50 \% \mathrm{~A}, 27.27 \% \mathrm{~T}, 25.98 \% \mathrm{C}$, and $13.25 \% \mathrm{G}$. The mitochondrial genome contained a major noncoding control region (D-loop region), two ribosomal RNA genes, 13 protein-coding genes, and 22 transfer RNA genes. Neighbor-joining and maximum-parsimony trees of Caprinae constructed using 13 mitochondrial protein-coding genes showed that the Liuyang black goat is phylogenetically closest to Hemitragus jemlahicus (the Himalayan tahr) and Blue sheep to form clade A. Tibetan antelopes clustered separately in clade B and so did sheep in clade C.
\end{abstract}

Key words: Liuyang black goat; Caprinae; Mitochondrial genome; Phylogenetic relationship 


\section{INTRODUCTION}

The goat was one of the first animals to be domesticated (MacHugh and Bradley, 2001; Cao et al., 2006; Zeder et al., 2006). It is a source of milk, meat, dung for fuel, and materials for clothing and building, such as hair, bone, and skin (Li et al., 2000; Tang et al., 2016). Ever since Nass and Nass (1963) discovered mitochondrial DNA (mtDNA), molecular biologists, geneticists, and breeders have studied it, and the rapid development of polymerase chain reaction (PCR) and sequencing technology has accelerated progress in studying mtDNA. The mitochondrial genome in animals has a $15-23-\mathrm{kb}$ double-stranded circular structure, and plays an important role in metabolism and apoptosis (MacHugh and Bradley, 2001).

Animal mtDNA is a covalent, closed, circular double-stranded DNA molecule. Because of its low molecular weight, simple and stable structure, and maternal inheritance it is ideal for studying animal origins, evolution, and differentiation (Mariotti et al., 2013). Mitochondria are important organelles within eukaryotic cells, because they are the cells' power plants; $95 \%$ of the energy present in cells is derived from mitochondrial oxidative phosphorylation. Except for red blood cells, all somatic animal cells contain mitochondria, which are the only organelles outside the nucleus that contain genes.

Structural analyses of the animal mitochondrial genome have shown that the mtDNA of most mammals consists of 37 genes and a non-coding sequence of variable length (the control region or D-loop). The 37 genes include 13 protein-coding genes, two ribosomal RNA (rRNA) genes, and 22 transfer RNA (tRNA) genes. The 13 protein- coding genes are cytochrome c oxidase subunits I, II, and III (COI, COII, and COIII), cytochrome b (Cytb), ATP synthase subunits ATPase6 and ATPase8, and seven subunits of NADH dehydrogenase $(N D 1, N D 2, N D 3, N D 4, N D 4 L, N D 5$, and ND6). The two rRNA genes are $12 s$ rRNA and 16s rRNA.

The mitochondrial genome is widely used to study species origins, molecular evolution, and for phylogenetic analysis. Luikart et al. (2001) analyzed hypervariable regions of the 481-bp mtDNA D-loop of 406 goats from 88 breeds, and classified them into three highly differentiated haplotype groups. There is only one haplotype in Central and Southeast Asia. Previous studies have found that goats and other domestic animals (cattle, sheep, and pigs) have a number of maternal origins; it is possible that these goats originated in Central Asia. Ye et al. (1998) studied the DNA of Yunnan goats, and found that Yunnan and Korean goats share the same ancestor, confirming to some extent the homology of Asian goats. Li et al. (2001) used 14 restriction endonucleases to digest the mtDNA of several sheep species (Mongolian, Ujumqin, $\mathrm{Hu}$, and small-tail Han), and detected 32 restriction sites and 16 restriction morphs. Among them, $B g l$ was polymorphic and $X h o I$ had no cut-off point. The 16 restriction morphs were sorted into two gene haplotypes, haplotype I and haplotype II. Haplotype I belonged to sheep mtDNA, and its amount of polymorphic $\mathrm{mtDNA}(\pi$ value $=0.0129 \%)$ indicated that the genetic diversity of goat mtDNA is low.

\section{MATERIAL AND METHODS}

\section{DNA, PCR amplification, and sequencing}

Ear samples were obtained from healthy adult Liuyang black goats in Hunan Province, China. Genomic DNA was extracted by the standard phenol-chloroform method. The quality 
of the DNA was examined by ultraviolet spectrophotometry after electrophoresis on a $0.5 \%$ agarose gel. Based on the mtDNA sequence of the Yunnan black goat (GenBank accession No. KF952601), 23 pairs of primers were designed using the Premier 5.0 software (Premier Biosoft International, Palo Alto, CA, USA) (Table 1).

Table 1. Primer sequences used in this study.

\begin{tabular}{|c|c|c|}
\hline Upstream prime (5'-3') & Downstream prime (5'-3') & Annealing temperature $\left({ }^{\circ} \mathrm{C}\right)$ \\
\hline cccagcettcctgttaactc & gtgcgtgcttcatggcctaa & 52.3 \\
\hline cataaagacgttaggtcaaggtgta & aacgctttcttaattgatggctgct & 53.5 \\
\hline gcctggtgatagctggttgt & ggattgcgctgttatcceta & 56.5 \\
\hline cgagaagaccetatggagcttta & ttgagttggaggctcagcctgat & 53.1 \\
\hline cettacgacctgccacatcc & gggtatgggeccgatagctt & 55.5 \\
\hline tcaagcatccccccacaaac & gatagggtggttgtggttga & 56.8 \\
\hline ttggaggctgaggaggacta & tcagcggttgatgaacatgg & 53.0 \\
\hline tctacttctcccgecgegaa & tcagggtgtccaaagaatca & 54.2 \\
\hline aactcccctgtttgtgtgat & ggcatccgttcagtcactct & 55.4 \\
\hline ccacgacgatactctgatta & gacctggaattgcgtctgtt & 54.6 \\
\hline tgaagacttaagcttcgattcct & aatgggcgagtgatgctttagtt & 52.8 \\
\hline caccaagggacaacatgaaca & tgaggctaggaggacggaggta & 56.2 \\
\hline aggccttcgctatggaataa & ttcgtaggctaggcttacag & 54.6 \\
\hline cataggatcggctcgcettc & attagttctgtagcggtgaatgt & 55.1 \\
\hline taaccttcttctccgactcc & tcatcaggcagccattagtg & 53.4 \\
\hline cgttatcgtcgecatcctta & ctatcttgaagctgagcgataa & 57.2 \\
\hline ccgcacccatcataataacc & ggtgcagatgtggaggaatg & 51.9 \\
\hline ccgetttcatccactaacaga & ttatctgggettgtgagatgg & 56.7 \\
\hline ccgctaacataactcaccac & tgggtgggtctttcggatgt & 54.8 \\
\hline tcccaccccaccactcacaa & gtagcatggcgcctaagata & 55.9 \\
\hline ggcacaaacctagtcgaatg & ggtgctgatagtgaggctatgg & 54.8 \\
\hline aggacagccagtcgaacatc & atctagtggacgggatacgc & 52.7 \\
\hline tccacatgcatattaagcacgta & cgtggatgcttgcatgtgta & 56.3 \\
\hline
\end{tabular}

The complete mtDNA was amplified by PCR and sequenced by Shanghai Biosune Co. Ltd., Shanghai, China. The PCR volume was $20 \mu \mathrm{L}$, and the reaction conditions were as follows: amplification by PCR was conducted under the following conditions: $94^{\circ} \mathrm{C}$ for $5 \mathrm{~min}$; 35 cycles of $94^{\circ} \mathrm{C}$ for $30 \mathrm{~s}, 55^{\circ} \mathrm{C}$ for $30 \mathrm{~s}$, and $72^{\circ} \mathrm{C}$ for $30 \mathrm{~s}$; and $72^{\circ} \mathrm{C}$ for $5 \mathrm{~min}$.

\section{Phylogenetic analysis}

The known mitochondrial genomes of 44 representative different species and breeds of Caprinae (20 domestic goats, 16 domestic and foreign sheep, 4 Blue sheep, 2 Hemitragus jemlahicus, and 2 Tibetan antelopes (Pantholops hodgsonii)) were used. We obtained the mitochondrial genome sequences of these species by searching the GenBank database (http://www.ncbi.nlm.nih.gov/) and referring to the literature (Table 2).

Sequence alignment, arrangement, and divergence analyses were conducted using the EditSeq and MegAlign programs of DNASTAR 5.02 (DNASTAR Inc., Madison, WI, USA). The base composition of, and the Kimura 2-parameter genetic distance between, the different species was determined using the MEGA4.1 software (Tamura et al., 2007). Phylogenetic tree was constructed using the neighbor-joining (NJ) and maximumparsimony (MP) methods in MEGA4.1. Support for individual branches was assessed based on bootstrap percentage values computed after 1000 replications with the closeststepwise-addition option. 
Table 2. Experimental samples used in this study.

\begin{tabular}{l|l|l|l|l|l}
\hline Species & GenBank No. & Code & Species & GenBank No. & Code \\
\hline Chuanzhong black goat & KP273589 & CH1 & Small-tail Hulunbuir sheep & KP702285 & SM1 \\
\hline Dazu black goat & KP271023 & DA1 & Qilian White Tibetan sheep & KP998473 & QI1 \\
\hline Xiangdong black goat & KM998968 & XI1 & Ganjia Tibetan sheep & KP998472 & GA1 \\
\hline Boer goat & KM233163 & BO1 & Huoba Tibetan sheep & KP998471 & HU1 \\
\hline Meigu goat & KM244714 & ME1 & Awang Tibetan sheep & KP998470 & AW1 \\
\hline Xinong Shaneng milk goat & KP195269 & XS1 & Viena sheep & KF938356 & VI1 \\
\hline Shaannan White goat & KP195268 & SH1 & Finnsheep & KF938355 & FI1 \\
\hline FuShun black goat & KP662716 & FU1 & & KF938354 & FI2 \\
\hline YouZhou Wu goat & KP677511 & YO1 & Kainuu gray sheep & KF938353 & KA1 \\
\hline Jining Qing goat & KP677510 & J11 & Oparino sheep & KF938352 & OP1 \\
\hline Hechuan white goat & KP677509 & HE1 & Duolang sheep & KF938332 & DU1 \\
\hline Intersexual goat & KP662714 & IN1 & Hanzhong sheep & KF938329 & HA1 \\
\hline Jianyang Daer goat & KM670319 & JY1 & Jingzhong sheep & KF938328 & JZ1 \\
\hline Nanjiang Yellow goat & KM093871 & NA1 & Hulun Buir sheep & KF938327 & HB1 \\
\hline Hainan black goat & KM360063 & HA1 & Qira Black sheep & KF938326 & QB1 \\
\hline Chinese Tibetan goat & KJ940969 & CT1 & Qinhai Tibetan sheep & KF938325 & QT1 \\
\hline Inner Mongolia white cashmere goat & GU068049 & IM1 & Blue sheep & KP998469 & BL1 \\
\hline Jintang black goat & KP231536 & JB1 & & KJ784494 & BL2 \\
\hline Liuyang black goat & KR866125 & LI1 & & NC_016689 & BL3 \\
\hline Yunnan black goat & KF952601 & YU1 & & JQ040802 & BL4 \\
\hline Tibetan antelope & NC_007441 & TI1 & Hemitragus jemlahicus & NC_020628 & HJ1 \\
\hline & DQ191826 & TI2 & & FJ207531 & HJ2 \\
\hline
\end{tabular}

\section{RESULTS}

\section{Characteristics of the Liuyang black goat mitochondrial genome}

The mitochondrial genome of the Liuyang black goat is a circular double-stranded DNA that is $16,715 \mathrm{bp}$ long (GenBank accession No. KR866125), and consists of $33.50 \% \mathrm{~A}$, $27.27 \% \mathrm{~T}, 25.98 \% \mathrm{C}$, and $13.25 \% \mathrm{G}$. The AT content (60.77\%) is significantly higher than the GC content (39.23\%), which is consistent with the base composition of mitochondrial genomes of other Caprinae species (Parma et al., 2003; Mereu et al., 2008; Zhang et al., 2016). In addition, as with other black goats and sheep (Li et al., 2002; Cañón et al., 2006), the mitochondrial genome contained two rRNA (12S and 16S rRNA), 22 tRNAs, 13 proteincoding genes (NADH dehydrogenase subunits 1, 2, 3, 4, 4L, 5, and 6; cytochrome c oxidase subunits I, II, and III; ATPase subunits 6 and 8; and cytochrome b), and one non-coding region (D-loop). Of these genes, only NADH dehydrogenase subunit 6 and eight tRNAs ( $t R N A^{G l n}$, $t R N A^{A l a}, t R N A^{A s n}, t R N A^{C y s}, t R N A^{T y r}, t R N A^{\text {Ser }}, t R N A^{\text {Glu }}$, and $t R N A^{P r o}$ ) were encoded in the L-strand, while the others were encoded in the $\mathrm{H}$-strand.

\section{Protein-coding genes}

The total length of the Liuyang black goat mtDNA that encodes 13 protein-coding genes was 11,760 bp. The longest gene was NADH5 (1821 bp), and the shortest was ATPase8 (198 bp; Table 3). In addition to ND2, ND3, and ND5 having ATA as initiation codons, the other protein-coding genes initiated with the start codon, ATG. Four types of termination codon were identified (Table 3). ND2, Cytb, and eight other genes ended with TAG, AGA, and TAA, respectively. $C O X 3, N D 3$, and $N D 4$ ended with an incomplete termination codon "T-", as observed in other Caprinae (Ee et al., 2015a,b). "T-" was at the 5'-terminal of the adjacent gene, and presumably formed the TAA stop codon by post-transcriptional polyadenylation (Anderson et al., 1981). As in other mammals, there were four overlapping reading frames, 
ATPase8/ATPase6, ATPase6/COIII, NADH4/NADH4L, and NADH5/NADH6, which overlapped by $40,1,7$, and $17 \mathrm{bp}$, respectively (Table 3 ).

\begin{tabular}{|c|c|c|c|c|c|c|c|c|c|c|}
\hline \multirow[t]{2}{*}{ Gene } & \multicolumn{2}{|c|}{ Position } & \multirow[t]{2}{*}{ Size (bp) } & \multicolumn{4}{|c|}{ Base composition (\%) } & \multirow{2}{*}{$\begin{array}{c}\text { Start } \\
\text { codon }\end{array}$} & \multirow{2}{*}{$\begin{array}{l}\text { Termination } \\
\text { codon }\end{array}$} & \multirow[t]{2}{*}{ Strand } \\
\hline & From & To & & A & $\mathrm{C}$ & $\mathrm{G}$ & $\mathrm{T}$ & & & \\
\hline tRNA $A^{\text {Phe }}$ & 1 & 68 & $68^{*}$ & 38.24 & 19.12 & 19.12 & 23.53 & & & $\mathrm{H}$ \\
\hline $12 S r R N A$ & 69 & 1023 & 955 & 36.62 & 23.82 & 18.05 & 21.51 & & & $\mathrm{H}$ \\
\hline$t R N A^{V a l}$ & 1025 & 1091 & 67 & 38.81 & 19.40 & 11.94 & 29.85 & & & $\mathrm{H}$ \\
\hline $16 S r R N A$ & 1092 & 2657 & 1566 & 37.33 & 20.61 & 17.42 & 24.63 & & & $\mathrm{H}$ \\
\hline$t R N A^{\text {Leu }}$ & 2664 & 2738 & 75 & 32.00 & 22.67 & 17.33 & 28.00 & & & $\mathrm{H}$ \\
\hline ND1 & 2741 & 3696 & 956 & 32.29 & 28.63 & 11.08 & 28.00 & ATG & TAA & $\mathrm{H}$ \\
\hline tRNA $A^{\text {Ile }}$ & 3697 & 3765 & 69 & 39.13 & 10.14 & 15.94 & 34.78 & & & $\mathrm{H}$ \\
\hline$t R N A^{G l n}$ & 3763 & 3834 & 72 & 36.11 & 30.56 & 9.72 & 23.61 & & & $\mathrm{~L}$ \\
\hline$t R N A^{M e t}$ & 3837 & 3905 & 69 & 27.54 & 23.19 & 18.84 & 30.43 & & & $\mathrm{H}$ \\
\hline ND2 & 3906 & 4947 & 1042 & 37.26 & 28.35 & 7.85 & 26.53 & ATA & TAG & $\mathrm{H}$ \\
\hline$t R N A^{T r p}$ & 4948 & 5014 & 67 & 37.31 & 17.91 & 16.42 & 28.36 & & & $\mathrm{H}$ \\
\hline$t R N A^{A l a}$ & 5020 & 5084 & 65 & 39.13 & 21.74 & 10.14 & 28.99 & & & $\mathrm{~L}$ \\
\hline$t R N A^{A s n}$ & 5086 & 5158 & 73 & 30.14 & 28.77 & 16.44 & 24.66 & & & $\mathrm{~L}$ \\
\hline$t R N A^{C y s}$ & 5191 & 5259 & 69 & 27.94 & 20.59 & 19.12 & 32.35 & & & $\mathrm{~L}$ \\
\hline$t R N A^{T y r}$ & 5259 & 5326 & 68 & 27.94 & 22.06 & 16.18 & 33.82 & & & $\mathrm{~L}$ \\
\hline$C O X 1$ & 5328 & 6872 & 1545 & 29.00 & 25.50 & 16.12 & 29.39 & ATG & TAA & $\mathrm{H}$ \\
\hline$t R N A^{S e r}$ & 6870 & 6940 & 71 & 33.33 & 27.54 & 14.49 & 24.64 & & & $\mathrm{~L}$ \\
\hline$t R N A^{A s p}$ & 6946 & 7014 & 69 & 39.71 & 14.71 & 14.71 & 30.88 & & & $\mathrm{H}$ \\
\hline COX2 & 7015 & 7698 & 684 & 35.23 & 23.98 & 13.30 & 27.49 & ATG & TAA & $\mathrm{H}$ \\
\hline$t R N A^{L y s}$ & 7702 & 7768 & 67 & 34.33 & 19.40 & 17.91 & 28.36 & & & $\mathrm{H}$ \\
\hline ATPase8 & 7770 & 7967 & 198 & 39.90 & 24.75 & 7.07 & 28.28 & ATG & TAA & $\mathrm{H}$ \\
\hline ATPase6 & 7928 & 8608 & 681 & 32.45 & 28.78 & 10.72 & 28.05 & ATG & TAA & $\mathrm{H}$ \\
\hline COX3 & 8608 & 9391 & 784 & 26.66 & 28.83 & 14.54 & 29.97 & ATG & T- & $\mathrm{H}$ \\
\hline tRNA $A^{G l y}$ & 9392 & 9460 & 69 & 34.78 & 20.29 & 14.49 & 30.43 & & & $\mathrm{H}$ \\
\hline ND3 & 9461 & 9806 & 346 & 31.21 & 27.75 & 11.27 & 29.77 & ATA & T- & $\mathrm{H}$ \\
\hline$t R N A^{A r g}$ & 9808 & 9876 & 69 & 40.58 & 10.14 & 11.59 & 37.68 & & & $\mathrm{H}$ \\
\hline$N D 4 L$ & 9877 & 10173 & 297 & 31.65 & 25.59 & 11.78 & 30.98 & ATG & TAA & $\mathrm{H}$ \\
\hline ND4 & 10167 & 11544 & 1378 & 31.93 & 29.17 & 10.67 & 28.23 & ATG & T- & $\mathrm{H}$ \\
\hline tRNA $A^{H i s}$ & 11545 & 11614 & 70 & 41.43 & 15.71 & 10.00 & 32.86 & & & $\mathrm{H}$ \\
\hline$t R N A^{S e r}$ & 11615 & 11675 & 61 & 33.33 & 21.67 & 15.00 & 30.00 & & & $\mathrm{H}$ \\
\hline$t R N A^{\text {Leu }}$ & 11676 & 11745 & 70 & 37.14 & 14.29 & 20.00 & 28.57 & & & $\mathrm{H}$ \\
\hline ND5 & 11746 & 13566 & 1821 & 33.33 & 28.67 & 10.82 & 27.18 & ATA & TAA & $\mathrm{H}$ \\
\hline ND6 & 13550 & 14077 & 528 & 42.42 & 28.79 & 7.20 & 21.59 & ATG & TAA & $\mathrm{L}$ \\
\hline tRNA $A^{G l u}$ & 14078 & 14146 & 69 & 39.13 & 21.74 & 11.59 & 27.54 & & & $\mathrm{~L}$ \\
\hline Cytb & 14151 & 15290 & 1140 & 31.93 & 28.16 & 13.07 & 26.84 & ATG & AGA & $\mathrm{H}$ \\
\hline$t R N A^{T h r}$ & 15294 & 15363 & 70 & 35.71 & 21.43 & 17.14 & 25.71 & & & $\mathrm{H}$ \\
\hline$t R N A^{\text {Pro }}$ & 15364 & 15428 & 65 & 34.85 & 27.27 & 13.64 & 24.24 & & & $\mathrm{~L}$ \\
\hline D-loop & 15429 & 16715 & 1287 & 31.27 & 25.74 & 14.03 & 28.96 & & & $\mathrm{H}$ \\
\hline
\end{tabular}

*Numbering starts with the 5'-position of $t R N A$-Phe. TAA, stop codon completed by addition of 3'-adenine residues to mtRNA. $\mathrm{H}$ and $\mathrm{L}$ denote heavy and light strands, respectively.

In the Caprinae species selected from GenBank, COI, COII, NADH4L, NADH4, NADH5, NADH6, and Cytb had the same lengths, initiation codons, and stop codons (Table 4). Some genes exhibited 1- to 3-bp changes in length. For example, $N A D H 2$ and $N A D H 3$ in the Tibetan antelope was 1 and 2 bp longer, respectively, at the 5 '-end than in other species, while $C y t b$ in $H$. jemlahicus was 1 bp shorter than in other species.

\section{Non-coding region (D-loop region)}

The complete length of the D-loop region was $1287 \mathrm{bp}$, and was located between tRNA-Pro and $t R N A$-Phe (Table 3). There were large differences in D-loop lengths between 
species of Caprinae, which ranged from 1014 to $1373 \mathrm{bp}$, probably because of the different number of repetitive motifs between species. The length of the core repeat sequence in the Caprinae species was 75 bp, and was GTA CAT AGT ATT AAT GTA ATA TAG ACA TTA TAT GTA TAA AGT ACA TTA AAT GTG ATT TAC CTC ATG CAT ATA AGC AC, which is repeated differently in different individuals and causes heteroplasmy.

Table 4. Lengths of protein-coding genes in mitochondrial genomes of the Liuyang black goat and other Caprinae.

\begin{tabular}{|c|c|c|c|c|c|c|}
\hline & $\mathrm{Ba}$ & $\mathrm{Bb}$ & $\mathrm{Bc}$ & $\mathrm{Bd}$ & $\mathrm{Be}$ & $\mathrm{Bf}$ \\
\hline NADHI & 956 & 955 & 955 & 956 & 956 & 957 \\
\hline $\mathrm{NADH2}$ & 1042 & 1042 & 1042 & 1042 & 1042 & 1044 \\
\hline $\mathrm{COI}$ & 1545 & 1545 & 1545 & 1545 & 1545 & 1545 \\
\hline COII & 684 & 684 & 684 & 684 & 684 & 684 \\
\hline ATPase8 & 198 & 201 & 201 & 201 & 198 & 201 \\
\hline ATPase6 & 681 & 679 & 681 & 681 & 681 & 681 \\
\hline COIII & 784 & 784 & 784 & 784 & 784 & 784 \\
\hline NADH3 & 346 & 346 & 346 & 346 & 346 & 347 \\
\hline NADH4L & 297 & 297 & 297 & 297 & 297 & 297 \\
\hline NADH4 & 1378 & 1378 & 1378 & 1378 & 1378 & 1378 \\
\hline NADH5 & 1821 & 1821 & 1821 & 1821 & 1821 & 1821 \\
\hline NADH6 & 528 & 528 & 528 & 528 & 528 & 528 \\
\hline Cytb & 1140 & 1140 & 1140 & 1140 & 1139 & 1140 \\
\hline
\end{tabular}

$\mathrm{Ba}$, domestic goats; $\mathrm{Bb}$, domestic and foreign sheep; Bc, small-tail Hulunbuir sheep, Huoba Tibetan sheep, Awang Tibetan sheep, and Ganjia Tibetan sheep; Bd, Blue sheep; Be, Hemitragus jemlahicus; Bf, Tibetan antelope.

The D-loop regions of sheep have 3-4 repeat units (75 bp), and Blue sheep have 2-3 repeat units. Two repeat units are in the D-loop regions of Tibetan antelope and H. jemlahicus. No repetitive motifs were detected in D-loop regions of goats. These repeat units are not completely repeated; as is shown in Figure 1, mutations in the repeat units were mainly located at the 8th, 20th, 60th, 66th, and 75th digits, which means that the 75-bp repeat units in the mtDNA D-loop are incompletely repeated, but are all of equal length (75 bp). Base differences led to the differences between these goats.

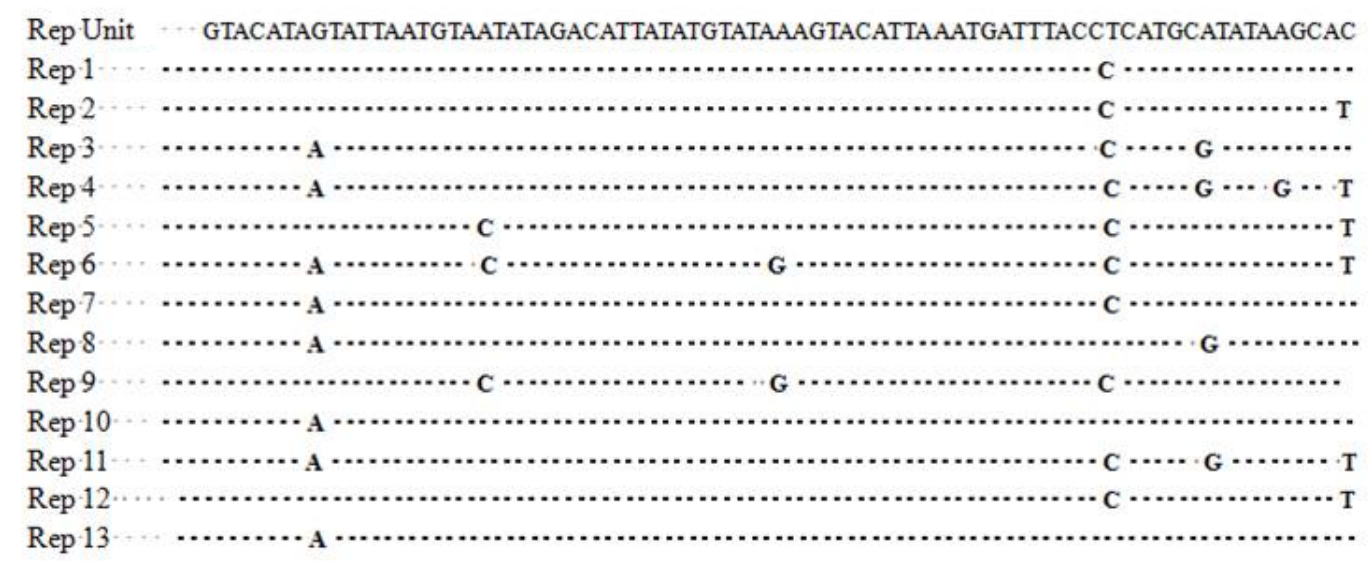

Figure 1. Repeat units of mtDNA D-loop sequence repeat region in sheep. 


\section{tRNA and rRNA genes}

There were 22 tRNA genes in the mitochondrial genome of the Liuyang black goat. Their lengths ranged from $65 \mathrm{bp}(t R N A-A l a)$ to $75 \mathrm{bp}(t R N A-L e u)$, and they were distributed in protein-coding genes and rRNA genes. The total length of the Liuyang black goat mtDNA that encodes the tRNA genes was $1512 \mathrm{bp} .12 S \mathrm{rRNA}$ and $16 S \mathrm{r} R N A$ were 955 and $1566 \mathrm{bp}$ in length, respectively, and were located between $t R N A-P h e$ and $t R N A-L e u$ and separated by $t R N A-\mathrm{Val}$, as is the case in other Caprinae. $12 S$ rRNA in the Liuyang black goat was $2 \mathrm{bp}$ longer than in the Chinese Tibetan goat or the Yunnan black goat, but $16 S$ rRNA was the same in length and location in all of the goats.

\section{Phylogenetic analysis}

Phylogenetic trees for 44 individuals of Caprinae based on the amino acid sequences of 13 protein-coding genes were constructed using NJ and MP methods (Figures 2 and 3). The topological structures of both trees were almost identical. We found that the Caprinae were divided into three groups: all of the goats, Blue sheep, and H. jemlahicus were clustered into clade A (99\%), Tibetan antelopes were alone in clade B (99\%), and all of the sheep were together in clade C $(99 \%)$. In clade A, goats and $\mathrm{H}$. jemlahicus clustered together first, and then clustered with Blue sheep. There were more individuals in clade A $(26,59.09 \%)$ than in clade B $(2,4.55 \%)$ or clade C $(16,36.36 \%)$.

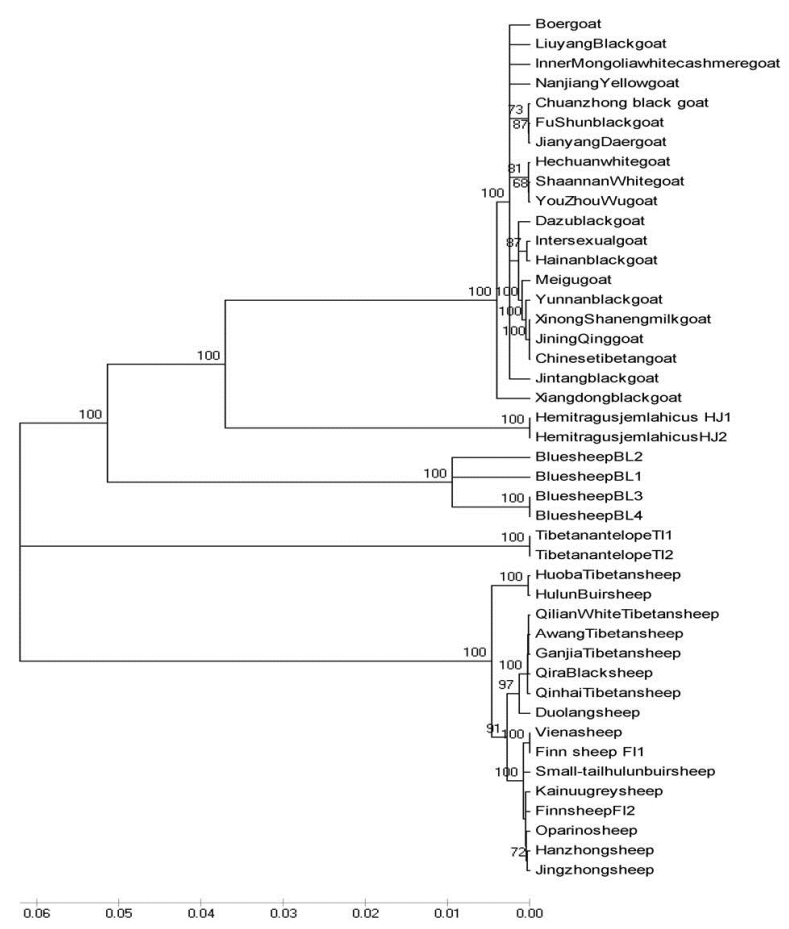

Figure 2. Neighbor-joining tree of Caprinae constructed from 13 mitochondrial protein-coding genes. 


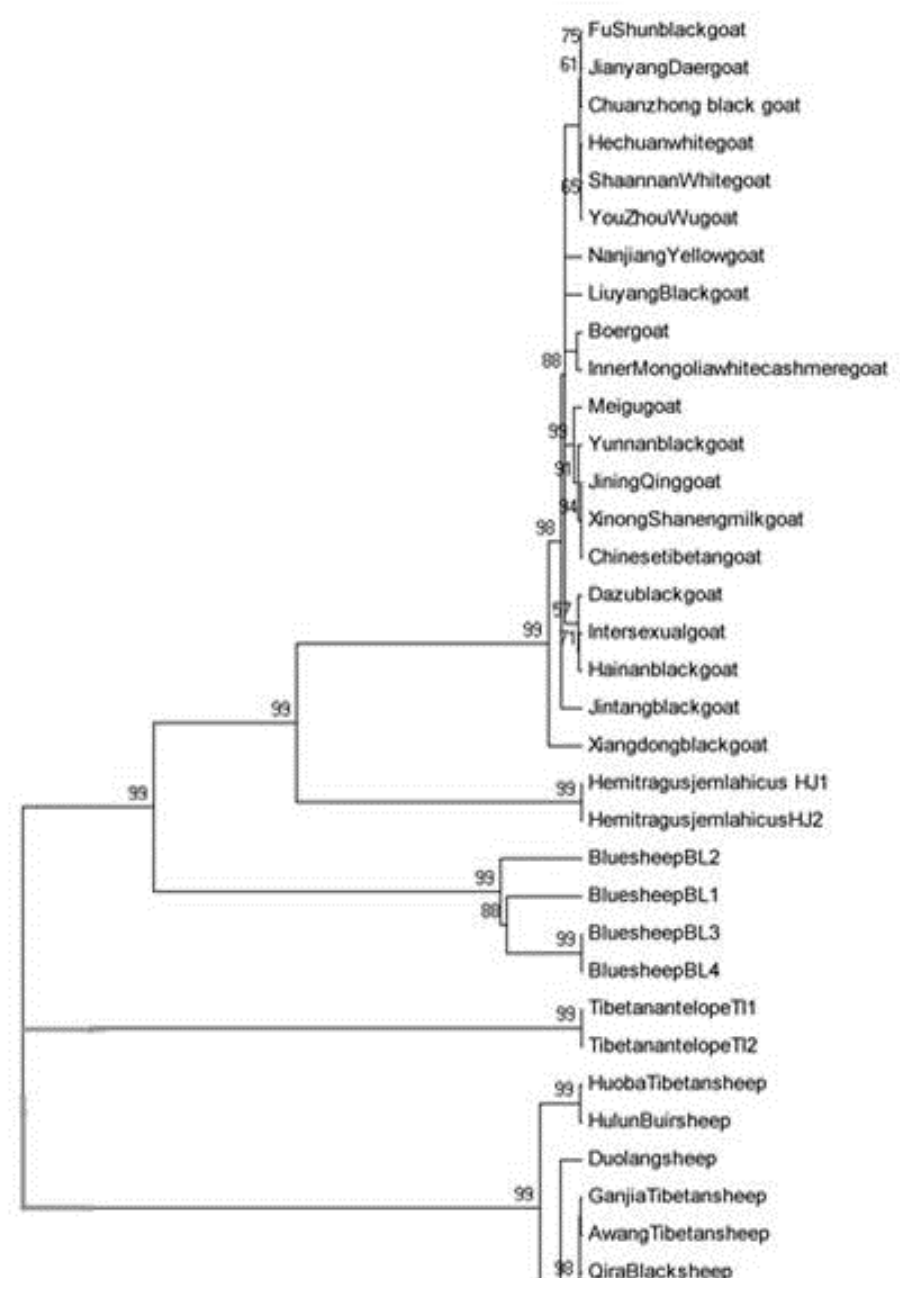

Figure 3. Maximum-parsimony tree of Caprinae constructed from 13 mitochondrial protein-coding genes.

\section{DISCUSSION}

The purpose of this study was to detail the characteristics of Liuyang black goat mtDNA, to compare its mtDNA sequence with those of other Caprinae, to determine the length and sequence variations of the genes, and to contribute to the reference mtDNA database of domestic goats. Phylogenetic trees using 13 protein-coding genes were constructed to determine phylogenetic relationships between the species studied.

Regarding gene content and arrangement in the mitochondrial genome, the Liuyang black goat sequence conforms to the mtDNAs of other Caprinae, both in size and composition. The mitochondrial DNA of animals is a small, extrachromosomal genome that is approximately $16 \mathrm{~kb}$ in length. Mitochondrial DNA in eukaryotes ranges from 6 to $2000 \mathrm{~kb}$ in length, e.g., human, 16,569 bp; Bovidae, 16,338 bp; and Muridae, 16,275 bp (Gardner, 1991; Palmer, 
1997). Parma et al. (2003), using cloning and conventional molecular biology techniques, found that the mitochondrial DNA sequence of goats is $16.64 \mathrm{~kb}$ long. The Liuyang black goat belongs to the Bovidae and the length of its mitochondrial DNA is $16,715 \mathrm{bp}$, which is consistent with being in that group.

The D-loop region in the goat is 1212 bp long and located between tRNA-Pro and tRNA-Phe (Parma et al., 2003; Wang and Chen, 2005). We found that the D-loop in Liuyang black goat mtDNA was $1287 \mathrm{bp}$ long, which generally agrees with the results of previous studies. A few differences in some bases may have been caused by bases being inserted or deleted, or by repeat motifs (75 bp). Sultana and Mannen (2004) found a 76-bp motif in the mtDNA of Pakistani domestic goats, and reported a 17-bp missing fragment in this region. In our study, we also found a motif in the D-loop, but the 17-bp missing fragment was not observed.

The D-loop region is more variable than other regions, and D-loop variation may indicate a history of past isolation, even in the event of the contemporary admixture of groups that evolved in allopatry (Huo et al., 2016). The mtDNA D-loop region has been used extensively in studying relationships between populations (Giuffra et al., 2000; Wu et al., 2014), because variation in this region is higher than in other mtDNA regions or nuclear genes.

Mitochondrial DNA is ideal for studying animal origins and evolution, as well as group genetic differentiation, because it is extranuclear and maternally inherited. Phylogenetic development was once investigated by studying mtDNA using restriction fragment length polymorphism (RFLP). Wilson and Cann (1992) used RFLP on mtDNA to investigate the intraspecific and interspecific evolutionary relationships of several fishes in the Salmonidae family. Most of the results that they obtained were consistent with the conclusions of classical morphological analysis.

In this study, we constructed phylogenetic trees for 44 individuals of Caprinae based on the amino acid sequences of 13 protein-coding genes using the NJ and MP methods (Figures 2 and 3). All of the domestic goats were clustered within a short genetic distance of each other, indicating that they are closely related and have a low level of genetic differentiation and a lack of genetic diversity. This is in agreement with the findings of previous studies in China and elsewhere (Luikart et al., 2001; Huang et al., 2008; Wang et al., 2008; Amills et al., 2009; Liu et al., 2009). After the domestic goats were clustered with H. jemlahicus, they were then clustered with Blue sheep to form clade A, and the frequency was $99 \%$. Some researchers hold the opinion that Blue sheep are the wild ancestors of goats $(\mathrm{Li}, 1993)$, and we found that goats and Blue sheep had a low level of divergence and were closely related, but cannot be certain whether Blue sheep are the wild ancestors of goats. More advanced sequencing technologies are required to investigate the mtDNA of wild goats. All of the sheep were closely related, and clustered together to form clade C. Among them, there was a short genetic distance between Huoba Tibetan sheep and Hulunbuir sheep and a large genetic distance between them and other sheep species, which may be associated with habitat differences. Tibetan antelopes were clustered together to form an independent clade B, and there was a relatively large genetic distance between them and sheep and goats, which may also be explained by habitat or ecological differences. Seasonal sexual isolation occurs in Tibetan antelopes when females migrate to give birth (Zhou et al., 2006), which may affect gene exchanges between different geographical populations. In addition, Tibetan antelopes live in a harsh, high-altitude environment, so hybridization is unlikely to occur frequently. Therefore, Tibetan antelopes have a close phylogenetic relationship with other Caprinae. 


\section{Conflicts of interest}

The authors declare no conflict of interest.

\section{ACKNOWLEDGMENTS}

Research supported by the National High Technology Research and Development Program of China (Grant \#2011AA 1003 04) and the Provincial Natural Science Foundation of Hunan (Grant \#13JJ1021).

\section{REFERENCES}

Amills M, Ramírez O, Tomàs A, Badaoui B, et al. (2009). Mitochondrial DNA diversity and origins of South and Central American goats. Anim. Genet. 40: 315-322. http://dx.doi.org/10.1111/j.1365-2052.2008.01837.x

Anderson S, Bankier AT, Barrell BG, de Bruijn MH, et al. (1981). Sequence and organization of the human mitochondrial genome. Nature 290: 457-465. http://dx.doi.org/10.1038/290457a0

Cañón J, García D, García-Atance MA, Obexer-Ruff G, et al.; ECONOGENE Consortium (2006). Geographical partitioning of goat diversity in Europe and the Middle East. Anim. Genet. 37: 327-334. http://dx.doi.org/10.1111/ j.1365-2052.2006.01461.X

Cao SY, Wu XB, Yan P, Hu YL, et al. (2006). Complete nucleotide sequences and gene organization of mitochondrial genome of Bufo gargarizans. Mitochondrion 6: 186-193. http://dx.doi.org/10.1016/j.mito.2006.07.003

Ee GX, Huang YF, Liu N, Zhao Y, et al. (2016a). Characteristics of the mitochondrial genome of four native goats in China (Capra hircus). Mitochondrial DNA, in press.

Ee GX, Huang YF, Narisu, Gao HJ, Zhao ZQ, et al. (2016b). A complete mitochondrial genome of Dazu Black goat. Mitochondrial DNA, 27: http://dx.doi.org/10.3109/19401736.2014.1003910

Gardner EJ (1991). Principles of genetics (8th edition). John Wiley \& Sons, NJ, USA.

Giuffra E, Kijas JM, Amarger V, Carlborg O, et al. (2000). The origin of the domestic pig: independent domestication and subsequent introgression. Genetics 154: 1785-1791.

Huang QH, Liu RY, Wu Y and Wang XQ (2008). Sequence analysis of genetic diversity of mitochondrial cytochrome b gene from Guizhou black goats. J. Anhui Agri. Sci. 36: 11240-11241.

Huo JH, Wei QP, Wan MC, Liu LX, et al. (2016). Population phylogenomic analysis and origin of mitochondrial DNA in Chinese domestic pig. Mitochondrial DNA A DNA MappSeq Anal 27: 892-895. http://dx.doi.org/10.3109/19401 $\underline{736.2014 .919492}$

Li MH, Zhao SH, Bian C, Wang HS, et al. (2002). Genetic relationships among twelve Chinese indigenous goat populations based on microsatellite analysis. Genet. Sel. Evol. 34: 729-744. http://dx.doi.org/10.1186/1297-9686-34-6-729

Li XL, Zheng G-R and Zhang YP (2000). The complete mitochondrial genome and phylogenetic affiliation analysis of sheep, goats and blue sheep. Acta Vet. Zootech. Sin 31: 289-295.

Li XL, Tian QQ, Liu ZT, Sun N, et al. (2001). Study on the RFLP of mtRNA in several native sheep breeds. Acta Vet. Zootech. Sin. 32: 295-298.

Li ZN (1993). Chinese sheep science. Agricultural Publishing House, Beijing.

Liu YP, Cao SX, Chen SY, Yao YG, et al. (2009). Genetic diversity of Chinese domestic goat based on the mitochondrial DNA sequence variation. J. Anim. Breed. Genet. 126: 80-89. http://dx.doi.org/10.1111/j.1439-0388.2008.00737.x

Luikart G, Gielly L, Excoffier L, Vigne JD, et al. (2001). Multiple maternal origins and weak phylogeographic structure in domestic goats. Proc. Natl. Acad. Sci. USA 98: 5927-5932. http://dx.doi.org/10.1073/pnas.091591198

MacHugh DE and Bradley DG (2001). Livestock genetic origins: goats buck the trend. Proc. Natl. Acad. Sci. USA 98: 5382-5384. http://dx.doi.org/10.1073/pnas.111163198

Mariotti M, Valentini A, Marsan PA and Pariset L (2013). Mitochondrial DNA of seven Italian sheep breeds shows faint signatures of domestication and suggests recent breed formation. Mitochondrial DNA 24: 577-583. http://dx.doi.org $\underline{10.3109 / 19401736.2013 .770493}$

Mereu P, Palici di Suni M, Manca L and Masala B (2008). Complete nucleotide mtDNA sequence of Barbary sheep (Ammotragus lervia). DNA Seq. 19: 241-245. http://dx.doi.org/10.1080/10425170701550599

Nass S and Nass MM (1963). Intramitochondrial fibers with DNA characteristics: enzymatic and other hydrolytic treatments. J. Cell Biol. 19: 613-629. http://dx.doi.org/10.1083/jcb.19.3.613 
Palmer JD (1997). Genome evolution. The mitochondrion that time forgot. Nature 387: 454-455. http://dx.doi. org/10.1038/387454a0

Parma P, Feligini M, Greeppi G and Enne G (2003). The complete nucleotide sequence of goat (Capra hircus) mitochondrial genome. Goat mitochondrial genome. DNA Seq. 14: 199-203. http://dx.doi.org/10.1080/1042517031000089487

Sultana S and Mannen H (2004). Polymorphism and evolutionary profile of mitochondrial DNA control region inferred from the sequences of Pakistani goats. Anim. Sci. J. 75: 303-309. http://dx.doi.org/10.1111/j.1740-0929.2004.00190.x

Tamura K, Dudley J, Nei M and Kumar S (2007). MEGA4: molecular evolutionary genetics analysis (MEGA) software version 4.0. Mol. Biol. Evol. 24: 1596-1599. http://dx.doi.org/10.1093/molbev/msm092

Tang YX, Liu F, Tang HX, Yang SK, et al. (2016). The complete mitochondrial genome of Yunnan black goat (Capra hircus). Mitochondrial DNA 27: 224-225. http://dx.doi.org/10.3109/19401736.2014.880900

Wang J and Chen YL (2005). Study on the goat breeds and genetic diversity in China. Acta Ecol. Anim. Domest 26: 4-6.

Wang J, Chen YL, Wang XL and Yang ZX (2008). The genetic diversity of seven indigenous Chinese goat breeds. Small Rumin. Res. 74: 231-237. http://dx.doi.org/10.1016/j.smallrumres.2007.03.007

Wilson AC and Cann RL (1992). The recent African genesis of humans. Sci. Am. 266: 68-73.

Wu YP, Huo JH, Xie JF, Liu LX, et al. (2014). Phylogeography and origin of Chinese domestic chicken. Mitochondrial DNA 25: 126-130. http://dx.doi.org/10.3109/19401736.2013.786704

Ye S, Peng H, Wang W and Liu A (1998). Restriction cleavage analysis of mtDNA extracted from the four conserved goat in Yunnan province. China Anim. Husband. J. 34: 11-12.

Zeder MA, Emshwiller E, Smith BD and Bradley DG (2006). Documenting domestication: the intersection of genetics and archaeology. Trends Genet. 22: 139-155. http://dx.doi.org/10.1016/j.tig.2006.01.007

Zhang H, Duan X, Li H, Niu L, et al. (2016). The complete mitochondrial genome of Chinese Tibetan goat (Capra hircus). Mitochondrial DNA A DNA MappSeq Anal 27: 1161-1162. http://dx.doi.org/10.3109/19401736.2014.936418

Zhou H, Li DQ, Zhang YG, Yi XR, et al. (2006). [Study on mitochondrial DNA genetic diversity of Tibetan antelope]. Yi Chuan 28: 299-305. 